\title{
Pleomorphic lobular carcinoma of the breast with osteoclast-like giant cells: a case report and review of the literature
}

Lourdes Peña-Jaimes ${ }^{1}$, Irene González-García ${ }^{1}$, María Eugenia Reguero-Callejas ${ }^{1,4}$, Ignacio Pinilla-Pagnon , Belén Pérez-Mies ${ }^{1,4,5}$, Víctor Albarrán-Artahona², Noelia Martínez-Jañez ${ }^{2,4}$, Juan Manuel Rosa-Rosa ${ }^{3,4}$ and José Palacios ${ }^{1,3,4,5^{*}}$

\begin{abstract}
Background: Breast carcinoma with osteoclast-like giant cells (OGCs) is infrequent, being most reported cased described as ductal invasive carcinomas. Invasive pleomorphic lobular carcinoma (PLC) is a distinct morphological variant of invasive lobular carcinoma characterized by higher nuclear atypia and pleomorphism than the classical type. In the best of our knowledge, a PLC with OGCs has not been previously reported.

Case presentation: We report the case of a 72-year-old woman presenting with a pleomorphic tumor of the left breast with a dense infiltration by OGCs and T lymphocytes with a 10:1 predominance of CD8+ over CD4+ cells. The diagnosis of a lymphoid or mesenchymal neoplasia was excluded after demonstrating keratin expression by the neoplastic cells. The absence of E-cadherin expression and the morphological features were consistent with the diagnosis PLC with OGCs. In addition, we demonstrated the deleterious mutation C.del866C in CDH1gene, but no mutations in any of the other 33 genes analyzed by next generation sequencing.

Conclusions: Breast carcinoma with stromal osteoclast-like giant cells is a very rare tumor, for that reason, the use of the cytologic features and growth patterns in combination with immunohistochemically studies is mandatory for a correct diagnosis of lobular carcinoma. In addition, further studies are necessary to clarify the influence of OGCs in the prognosis of these patients.
\end{abstract}

Keywords: Pleomorphic carcinoma, Osteoclast-like giant cells, Breast cancer, Lobular carcinoma

\section{Background}

Breast carcinoma with stromal osteoclast-like giant cells (OGCs) was described by Agnatis and Rosen in 1979 [1], and accounts for $0.5-1.2 \%$ of all carcinomas of the breast [1-3]. Although the origin of the OGCs is controversial, immunohistochemical studies suggest a benign histiocytic origin as a response to cytokines produced by tumor cells in the process of angiogenic stimulation [1, 2, 4-9].

The majority of infiltrating breast carcinomas with OGCs described in the literature are invasive ductal carcinomas $[1-3,10]$. Despite being reported in other

\footnotetext{
* Correspondence: jose.palacios@salud.madrid.org

${ }^{1}$ Department of Pathology, Hospital Ramón y Cajal, Madrid, Spain

${ }^{3}$ CIBER-ONC, Insituto de Salud Carlos III, Madrid, Spain

Full list of author information is available at the end of the article
}

subtypes, to date, there have been few reported cases of invasive lobular carcinomas with OGCs [1, 6-9].

The aim of this study is to report the first pure pleomorphic lobular carcinoma of the breast with osteoclast-like giant cells in a 72-year-old woman. The diagnosis of lobular carcinoma was confirmed by immunohistochemistry (loss of expression of E-cadherin), and by targeted next generation sequencing, which identified a CDH1 mutation. Immunohistochemical analysis demonstrated a predominant histiocytic and $\mathrm{T}$ lymphocyte inflammatory response and no expression of PDL-1 in tumor or inflammatory cells. In addition, we present a literature review of the association of lobular carcinoma and OGCs.

(c) The Author(s). 2018 Open Access This article is distributed under the terms of the Creative Commons Attribution 4.0 International License (http://creativecommons.org/licenses/by/4.0/), which permits unrestricted use, distribution, and reproduction in any medium, provided you give appropriate credit to the original author(s) and the source, provide a link to the Creative Commons license, and indicate if changes were made. The Creative Commons Public Domain Dedication waiver (http://creativecommons.org/publicdomain/zero/1.0/) applies to the data made available in this article, unless otherwise stated. 


\section{Case presentation}

A 72-year-old woman was referred to our hospital with one-month history of a palpable mass with burning sensation in her left breast. Mammography revealed a nodular increased density of the upper inner quadrant of the left breast considered to be suspicious of malignancy, Breast Imaging Reporting and Data System category 5 (BI-RADS-5).

Ultrasound revealed a hypoechoic mass with irregular and poorly defined margins measuring $23 \mathrm{~mm} \times 14 \mathrm{~mm}$. The ipsilateral axillary lymph nodes were normal. After a diagnosis of malignancy on core needle biopsy, the patient underwent simple mastectomy of the left breast and sentinel lymph node biopsy.

On gross examination, two neighboring foci were found measuring together $28 \mathrm{~mm} \times 17 \mathrm{~mm}$. There were ill-defined whitish lesions with soft red-brown areas inside. No nipple and periareolar lesion were seen. Histologically, both tumor foci were identical, and similar features were observed in the 6 sections examined. The tumor showed high cellularity arranged in sheet of discohesive cells with large cytoplasm and marked nuclear atypia. The tumour cells showed 15 mitosis per high power microscopic field. The lesion included numerous osteoclast-like giant cells containing many small uniform nuclei and hemosiderin-laden macrophages. The stroma was loose, highly vascular with hemorrhagic areas and foci of chronic inflammatory infiltration. Some carcinomas in situ foci were also identified at the periphery of the infiltrating tumour (Fig. 1).

One of the three sentinel lymph nodes analyzed using routine intraoperative One-Step Nucleic Acid Amplification (OSNA) assay showed metastasis (17,000 copies/uL). Subsequently, ipsilateral axillary dissection was performed and no additional metastases were found in 14 additional lymph nodes resected.

The immunohistochemical study (see Additional file 1: Table S1) demonstrated the epithelial nature of the neoplasia, since the tumour cells expressed both cytokeratins AE1/AE3 and CK19 that were positive. Due to the discohesive nature of the cells, immunostaining for E-cadherin was performed and demonstrated complete absence of expression in both, the in situ and the invasive components. On the contrary, giant cells were negative for cytokeratin expression but were strong positive for the histiocytic marker CD68. With these features, the diagnosis was of invasive pleomorphic lobular carcinoma (histological grade 3) with OGCs (Fig. 2).

Biomarker analysis demonstrated that the carcinoma was estrogen receptor (ER) positive (strong positivity in $90 \%$ of tumor cells); progesterone receptor (PR) negative (complete absence of expression); and demonstrated lack of overexpression of human epidermal growth factor receptor type 2 (HERCEPTEST 1+). The Ki67 cellular

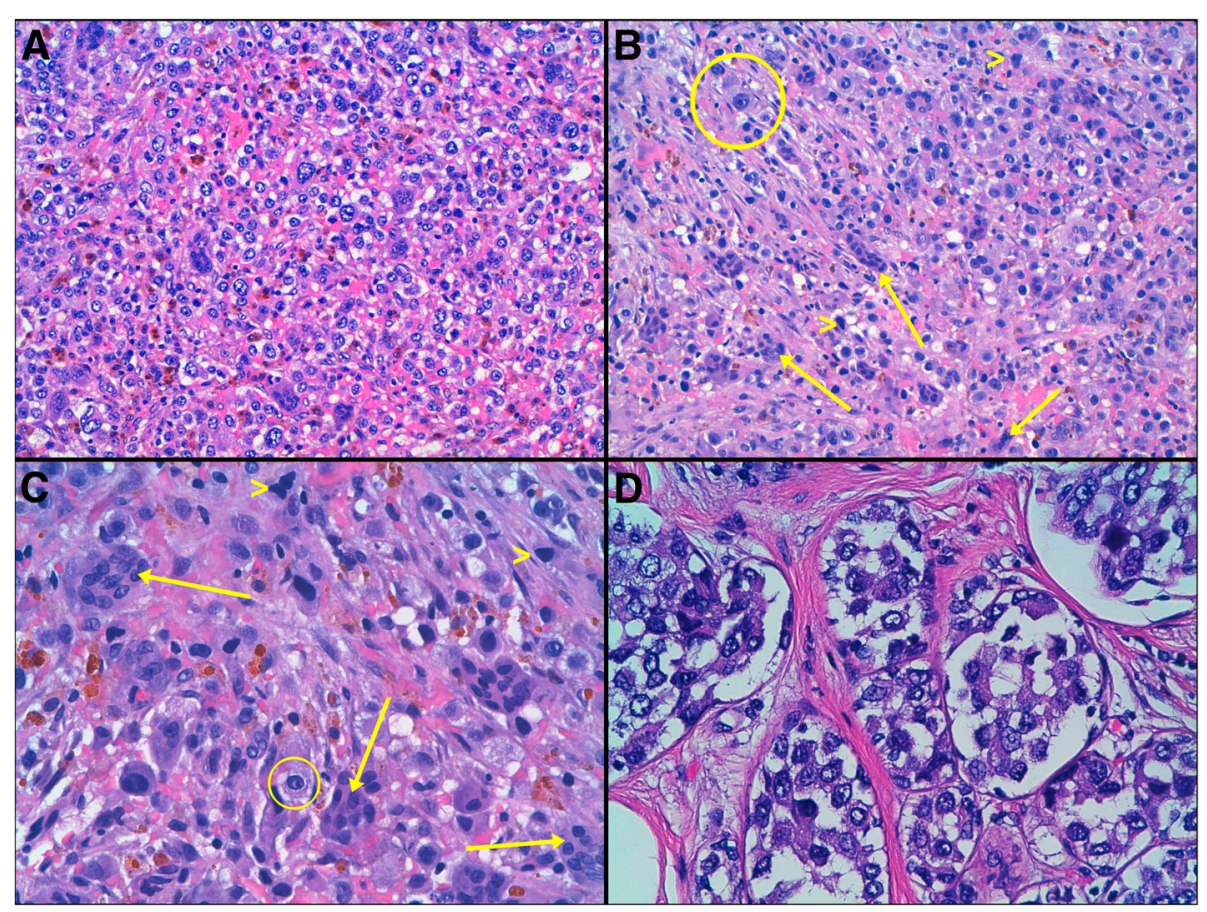

Fig. 1 Histological findings (H-E). a 20x magnification, Heterogeneous proliferation of cells in a highly vascular stroma with hemorrhagic areas, hemosiderin-laden macrophages and chronic inflammatory infiltration. b 20x magnification and c 40x magnification. Numerous osteoclast-like giant cells that vary in shape and size with an eosinophilic cytoplasm (arrows).Marked nuclear atypia: Vesicular appereance, hyperchromatic (head of arrow) or with prominent nucleolus (circle). $\mathbf{d} 40 \times$ magnification, Focus of carcinoma in situ with the same nuclear atypia 


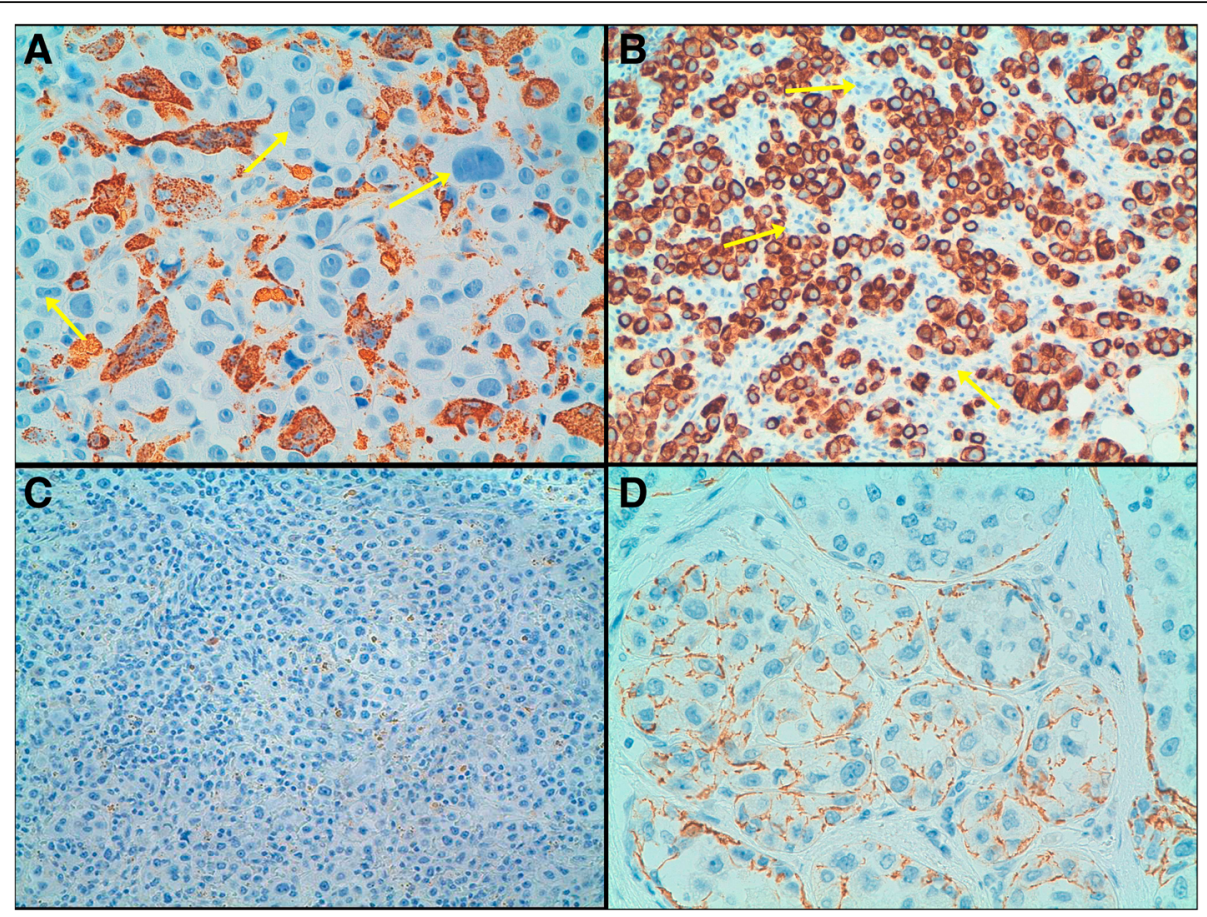

Fig. 2 Inmunohistochemistry. a Osteoclast-like giant cells were positive for CD68. In contrast, neoplastic cells were negative for CD68 (arrows). b Neoplastic cells were positive for cytokeratin (CK) AE1/AE. In contrast, Osteoclast-like giant cells were negative for CK AE1/AE3 (arrows). Both (c) the invasive component and (d) the in situ component showed complete absence of expression for E-cadherin

proliferation index was $18 \%$. The analysis of immune related markers demonstrated that, after counting at least $10 \mathrm{HPF}$, the tumors has a mean of $34 \mathrm{CD} 3+$ lymphocytes per 1HPF, 22 CD8+ lymphocytes per 1HPF, 2 CD4+ lymphocytes per $1 \mathrm{HPF}$, and $1 \mathrm{CD} 20+$ lymphocyte per $1 \mathrm{HPF}$. Only occasional tumor cells (less than 1\%) were PDL-1 + .

The tumor was subjected to molecular analysis by targeted next generation sequencing. DNA was extracted from a punch focused on the area with greater tumour cell density by using QIAamp DNA FFPE Tissue Kit (QIAGEN). Quantification $(447 \mathrm{ng} / \mu \mathrm{l})$ and qualification (DIN $=4.6)$ of the DNA was performed using a Tape Station 2200 (Agilent) and the Genomic DNA kit. We used an in-house panel based on hybrid capture for sequence enrichment including the 34 genes frequently mutated in breast cancer (AKT1, ARID1A, ARID1B, BRCA1, BRCA2, CASP8, CCND1, CDH1, ERBB2, ESR1, FGFR1, GATA3, GRB7, GSDMB, MAP2K4, KRAS, MAP3K1, MLL3, MYC, NCOR1, NF1, PGAP, PIK3CA3, PNMT, PTEN, RB1, SF3B1, STARD3, TBX3, TCAP, TP53, VGLL1, ZNF217, ZNF703) and regions in chromosome 8 (targeting amplification of FGFR1 and MYC), chromosome 11 (targeting amplification of CCND1), chromosome 17 (targeting amplification of $E R B B 2$ ) and chromosome 20 (targeting amplification of ZNF217). With this technique, we identified a deleterious mutation (C.del866C) in CDH1 (the gene coding for E-cadherin protein) (Fig. 3).
The patient was enrolled in a trial that studies giving tamoxifen with or without combination chemotherapy in postmenopausal women who have undergone surgery for breast cancer. The patient was randomized on the arm for receiving only hormone treatment. The patient remains well without evidence of recurrence or metastases two years after surgery.

\section{Discussion}

The differential diagnosis in present case included both lymphoid and mesenchymal neoplasias, due to the diffuse growth pattern, the abundance of inflammatory cells and the presence of OGCs. However, the expression of cytokeratins in pleomorphic neoplastic cells allowed the diagnosis of invasive breast carcinoma. The histological type of present tumor was only suspected after the observation of the in situ component, which was concordant with an in situ lobular carcinoma. The absence of E-cadherin expression in both the in situ and invasive components, the cytological features of the tumors and the presence of CD68-positive OGCs were consistent with the final diagnosis of pheomorphic lobular Carcinoma with OGCs.

Breast carcinoma with osteoclast-like giant cells is a rare entity that accounts for less than $2 \%$ of all carcinomas of the breast [1-3]. After its first description by Agnatis and Rosen in 1979 [1], approximately 200 cases 


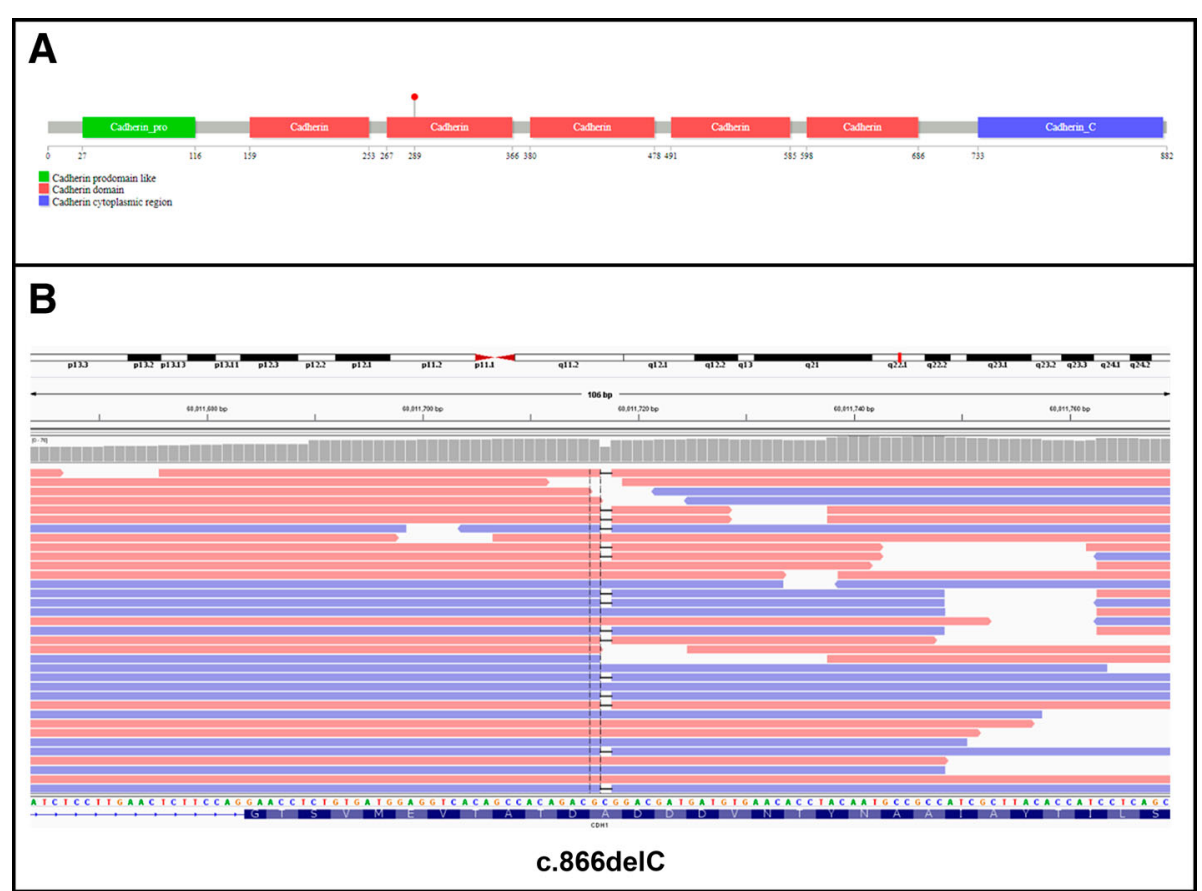

Fig. 3 Deleterious mutation in $\mathrm{CDH} 1$ found in the case studied. a Lollipop representation of deleterious mutation c.866delC in CDH1. E-cadherin motifs are represented in different colours. $\mathbf{b}$ IGV-browser view of mutation c.del866C through massive sequencing data from the case studied. Mutation is represented in both DNA strands ( $5^{\prime}->3^{\prime}$, red, and $3^{\prime}->5^{\prime}$, blue) in a high frequency of reads, supporting a homozygous status (through LOH) within tumour cells

have been published. Among the histological types of breast carcinoma with OGCs that have been reported, invasive ductal carcinoma is the most frequent $[1-3,10]$. In the best of our knowledge, only 7 previous invasive lobular carcinoma (ILC) with OGCs have been described in literature, but none of these had confirmation of the histological type by E-cadherin immunohistochemistry and/or mutational analysis of $C D H 1$ gene nor were of pleomorphic subtype. (Table 1) [1, 6-9]. Regarding the histological subtypes of previous ILC with OGCs, 5 cases were described as classical ILC (one of them bilateral) and two as alveolar ILC. Two reported cases were mixed invasive ductal and invasive lobular carcinomas with OGCs. Since there is no description of E-cadherin staining in these reports, the possibility of ductal carcinoma with areas of "lobular" growth cannot be excluded. In this sense, it has been reported that more than two third of mixed ductal-lobular carcinomas do not have $C D H 1 \mathrm{mu}-$ tations and their mutational and transcriptional profiles are suggestive of invasive ductal carcinoma [11].

Pleomorphic Lobular Carcinoma (PLC) was first described in 1987 by Page and represents less than $1 \%$ of all

Table 1 Summary 7: published cases of invasive lobular carcinoma of the breast with Osteoclast-like giant cells

\begin{tabular}{llllll}
\hline Reference & Yr of publication & Age $(\mathrm{yr})$ & Site & Size (cm) & Type of carcinoma \\
\hline Agnatis 1 & 1979 & 50 & NA & 0.5 & ILC, IDC \\
& & 43 & Left (UOQ) & 3.6 & ILC \\
Pettinato 7 & 48 & Left (UOQ) & 5.0 & ILC, IDC \\
Reale 8 & 1989 & 40 & Right (UOQ) & $2.0 \times 2.0$ & ILC alveolar variant \\
Takahashi 9 & 1993 & 63 & Left (LOQ) & 3.5 & ILC alveolar variant \\
lacocca 10 & 1998 & 48 & Right (UOQ) & $1.5 \times 1.5$ & ILC \\
& 2001 & 46 & Left (UIQ) & $11 \times 5.9$ & ILC \\
\hline
\end{tabular}


invasive breast carcinomas $[12,13]$. However, the diagnostic criteria of PLC are not fully defined. The World Health Organization (WHO) [14] describes it as a variant of the ILC that retains the distinctive growth pattern of classic lobular carcinoma, but showing a greater degree of cellular atypia and pleomorphism and a higher mitotic rate than classic ILC. As for classic ILC, loss of expression of E-cadherin, together with $C D H 1 \mathrm{LOH}$, is a nearly constant finding of PLC $[15,16]$.

In addition to the absence of E-Cadherin expression, we demonstrated the $C D H 1$ mutation $866 \mathrm{delC}$ by targeted next generation sequencing. No other alterations were observed in any of the remaining 33 genes analyzed for mutations or in the 5 regions analyzed for gene amplification. Recently, three large studies $[11,17,18]$ have reported the molecular alterations of lobular carcinomas. Although with some differences among studies, some of the most common alterations detected were mutations in $\mathrm{CDH} 1$ (42.8\% to $65 \%$ ), PIK3CA (34.8\% to $48 \%$ ), TBX3 (9\% to $13.3 \%$ ), FOXA1 7\% to (9\%), GATA3 (5\% to $7.1 \%$ ), MAP3K1 (5.1\% to $6 \%$ ), and AKT1 (2.5\% to $5.1 \%)$. Compared with classical ILC, a higher frequency of HER2 mutations have been identified in PLC (20.8\%) [19].

A recent genome-wide gene expression study [18] suggested the existence of two main subtypes of ILC: an immune related subtype (IR), characterized by lymphocytic infiltration and up-regulation of "checkpoint proteins", and a hormone related subtype, characterized by active ER/PR signaling and Epithelial to Mesenchymal Transition (EMT). The IR subtype showed high expression of numerous cytokine/chemokine signaling pathway components found in lymphoid cells, and over-expression of CD8 and CD4. Although we did not perform gene expression analysis, probably present case represents an example of IR-ILC, since our immnuhistochemical study demonstrated, together with a high number of OGCs, a heavy infiltration by $\mathrm{T}$ lymphocytes with 10:1 predominance of CD8+ over CD4+ cells. Although as a group the IR tumours also had high expression of the negative regulators of immune response PDCD1 (PD-1), CD274 (PD-L1) and CTLA4 (CTLA-4), immunohistochemical expression of these markers was only observed in some cases. According to these observations, our case did not show PDL-1 expression in tumor or inflammatory cells.

The prognostic significance of the presence of OGCs in breast carcinomas, remains controversial since some authors suggested a less favorable prognosis for invasive breast cancer with OGCs $[1,2]$, whereas others reported a similar or better prognosis than the infiltrative carcinomas without OGCs [10, 18]. Given this discrepancy, it is probably that the prognosis is more related to the type of cancer associated than to the presence or not of the OGCs. In this sense, it has been described that PLC has a worse prognosis than classical ILC [13, 20-22].

\section{Conclusion}

- Breast carcinoma with stromal osteoclast-like giant cells is a very rare tumor. Among the few reported cases, the association of OGCs with invasive lobular carcinoma is even rarer.

- It was of importance the use of the cytologic features and growth patterns in combination with inmunohistochemical studies, in this case, loss of E-cadherin expression, for a correct diagnosis of lobular carcinoma.

- The mechanism of formation of osteoclast-like giant cells is still unknown. However, most of the cases described support a non-epithelial, stromal histiocytic origin.

- The influence of OGCs in the prognosis of patients is still controversial. Nonetheless some studies suggest that the prognosis may be more related to the type of cancer associated rather than the presence or not of the OGGs.

- Further studies are needed to gain more comprehension of this rare tumor and determine future treatment strategies.

\section{Additional file}

Additional file 1: Table S1. Antibodies used for the

immunohistochemical study of case reported. (DOCX $16 \mathrm{~kb}$ )

\section{Abbreviations}

ILC: Invasive lobular carcinoma; OGCs: Osteoclast-like giant cells; PLC: Pleomorphic lobular carcinoma

\section{Funding}

This project was supported by grants from Instituto Carlos III (ISCIII) (PI16/00887, PT13/0010/0056, PIE15/00050) and CIBERONC (CB16/12/00316), co-financed by the European Development Regional Fund. 'A way to achieve Europe' (FEDER), by the AECC (AIO-AECC 2016) and by Fundació La Marató de TV3 (2/C2013). JMRR is a PhD researcher funded by ISCIII (CB16/12/00316).

\section{Availability of data and materials}

The datasets used and/or analyzed during the current study are available from the corresponding author on reasonable request.

\section{Authors' contributions}

LPJ, IGG, IPP, performed the gross and histological examination. MERC, BPM, JP performed the histological examination. VAA, NMJ decided the treatment and follow-up of the patient. JMRR performed the NGS assay and data analysis. LPJ, JP and JMRR redacted the manuscript. All the authors read and approved the final manuscript.

\section{Ethics approval and consent to participate}

Approval for the study was obtained from the Ethical Committee in Clinical Research (Hospital Universitario Ramón y Cajal, Insituto Ramón y Cajal de Investigación Sanitaria, IRyCIS) and written informed consent was obtained from all study participants.

Consent for publication

Written consent for publication was obtained from the patient.

Competing interests

The authors declare that they have no competing interests. 


\section{Publisher's Note}

Springer Nature remains neutral with regard to jurisdictional claims in published maps and institutional affiliations.

\section{Author details}

'Department of Pathology, Hospital Ramón y Cajal, Madrid, Spain.

2Department of Oncology, Hospital Ramón y Cajal, Madrid, Spain.

${ }^{3}$ CIBER-ONC, Insituto de Salud Carlos III, Madrid, Spain. ${ }^{4}$ Instituto Ramón y

Cajal de Investigación Sanitaria, Madrid, Spain. ${ }^{5}$ Universidad de Alcalá de

Henares, Madrid, Spain.

Received: 21 May 2018 Accepted: 20 August 2018

Published online: 28 August 2018

\section{References}

1. Agnantis NT, Rosen PP. Mammary carcinoma with osteoclast-like giant cells. A study of eight cases with follow-up data. Am J Clin Pathol. 1979;72(3): 383-9.

2. Holland R, van Haelst UJ. Mammary carcinoma with osteoclast-like giant cells. Additional observations on six cases. Cancer. 1984;53(9):1963-73.

3. Cai N, Koizumi J, Vazquez M. Mammary carcinoma with osteoclast-like giant cells: a study of four cases and a review of literature. Diagn Cytopathol. 2005;33(4):246-51.

4. Kurokawa K, Mouri Y, Asano A, Kamei K, Iwata $Y$, Isogai M, et al. Pleomorphic carcinoma with osteoclastic giant cells of the breast: immunohistochemical differentiation between coexisting neoplastic and reactive giant cells. Pathol Int. 2009;59(2):91-7.

5. Nielsen BB, Kiaer HW. Carcinoma of the breast with stromal multinucleated giant cells. Histopathology. 1985;9(2):183-93.

6. Pettinato G, Manivel JC, Picone A, Petrella G, Insabato L. Alveolar variant of infiltrating lobular carcinoma of the breast with stromal osteoclast-like giant cells. Pathol Res Pract. 1989;185(3):388-94. discussion 94-6

7. Reale D, Guarino M, Bianchini E, Crescini C, Pascale M, Mazzolari M, et al. Infiltrating lobular carcinoma of the breast, alveolar variant, with stromal reactive osteoclastlike giant cells. Description of a case. Pathologica. 1993:85(1099):525-32.

8. Takahashi T, Moriki T, Hiroi M, Nakayama H. Invasive lobular carcinoma of the breast with osteoclastlike giant cells. A case report. Acta Cytol. 1998; 42(3):734-41.

9. lacocca MV, Maia DM. Bilateral infiltrating lobular carcinoma of the breast with osteoclast-like giant cells. Breast J. 2001;7(1):60-5.

10. Zhou S, Yu L, Zhou R, Li X, Yang W. Invasive breast carcinomas of no special type with osteoclast-like giant cells frequently have a luminal phenotype. Virchows Arch. 2014;464(6):681-8.

11. Ciriello G, Gatza ML, Beck AH, Wilkerson MD, Rhie SK, Pastore A, et al. Comprehensive molecular portraits of invasive lobular breast Cancer. Cell. 2015;163(2):506-19.

12. Page $\mathrm{DL}$, Anderson TJ. Diagnostic histopathology of the breast. Edinburgh: Churchill Livingstone; 1997. p. 362.

13. Eusebi V, Magalhaes F, Azzopardi JG. Pleomorphic lobular carcinoma of the breast: an aggressive tumor showing apocrine differentiation. Hum Pathol. 1992;23(6):655-62.

14. WHO. In: Kurman RJ, Carcangiu ML, Herrington S, Young RH, editors Classification of Tumours of the Female Reproductive Organs. Lyon: International Agency for Research on Cancer; 2014.

15. Palacios J, Sarrio D, Garcia-Macias MC, Bryant B, Sobel ME, Merino MJ. Frequent E-cadherin gene inactivation by loss of heterozygosity in pleomorphic lobular carcinoma of the breast. Mod Pathol. 2003;16(7):674-8.

16. Simpson PT, Reis-Filho JS, Lambros MB, Jones C, Steele D, Mackay A, et al. Molecular profiling pleomorphic lobular carcinomas of the breast: evidence for a common molecular genetic pathway with classic lobular carcinomas. J Pathol. 2008;215(3):231-44.

17. Desmedt C, Zoppoli G, Gundem G, Pruneri G, Larsimont D, Fornili M, et al. Genomic characterization of primary invasive lobular breast Cancer. J Clin Oncol. 2016;34(16):1872-81.

18. Michaut M, Chin SF, Majewski I, Severson TM, Bismeijer T, de Koning L, et al. Integration of genomic, transcriptomic and proteomic data identifies two biologically distinct subtypes of invasive lobular breast cancer. Sci Rep. 2016;6:18517.

19. Lien HC, Chen $Y L$, Juang $Y L$, Jeng YM. Frequent alterations of HER2 through mutation, amplification, or overexpression in pleomorphic lobular carcinoma of the breast. Breast Cancer Res Treat. 2015;150(2):447-55.
20. Buchanan CL, Flynn LW, Murray MP, Darvishian F, Cranor ML, Fey JV, et al. Is pleomorphic lobular carcinoma really a distinct clinical entity? J Surg Oncol. 2008;98(5):314-7.

21. Middleton LP, Palacios DM, Bryant BR, Krebs P, Otis CN, Merino MJ. Pleomorphic lobular carcinoma: morphology, immunohistochemistry, and molecular analysis. Am J Surg Pathol. 2000;24(12):1650-6.

22. Weidner N, Semple JP. Pleomorphic variant of invasive lobular carcinoma of the breast. Hum Pathol. 1992;23(10):1167-71.

\section{Ready to submit your research? Choose BMC and benefit from:}

- fast, convenient online submission

- thorough peer review by experienced researchers in your field

- rapid publication on acceptance

- support for research data, including large and complex data types

- gold Open Access which fosters wider collaboration and increased citations

- maximum visibility for your research: over $100 \mathrm{M}$ website views per year

At BMC, research is always in progress.

Learn more biomedcentral.com/submissions 